ORIGINAL ARTICLE

\title{
Are health professionals getting caught in the crossfire? The personal implications of caring for trauma victims
}

\author{
J M Crabbe, D M G Bowley, K D Boffard, D A Alexander, S Klein
}

Emerg Med J 2004;21:568-572. doi: 10.1136/emj.2003.008540

See end of article for authors' affiliations .....................

Correspondence to: Dr J M Crabbe, Aberdeen Centre for Trauma Research, Bennachie Building, Royal Cornhill Hospital, Aberdeen AB15 7PH, UK; jilliancrabbe@ hotmail.com

Accepted for publication 27 August 2003
Objectives: To investigate the long term psychological sequelae of treating multiple victims of traumatic incidents, such as violent crime and motor vehicle accidents, and to assess staff exposure to violent patients in the emergency department.

Methods: A self administered questionnaire booklet was distributed to all full time and part time staff working within the Johannesburg Hospital Trauma Unit during September 2002. Participation was voluntary. The questionnaire was specifically designed for the study as no relevant, validated questionnaire was found to be suitable. Psychological assessment comprised two standardised measures, the impact of event scale-revised and the Maslach burnout inventory.

Results: Thirty eight staff members completed the questionnaire, a response rate of $90 \%$. Over $40 \%$ of respondents had been physically assaulted while at work and over $90 \%$ had been verbally abused. Staff reported a significant level of post-traumatic symptoms, evaluated by the impact of event scale-revised (median $=17.5$, range $=0-88$ ), as a result of critical incidents they had been involved in during the previous six months. At least half of the respondents also reported a "high" degree of professional burnout in the three sub-scales of the Maslach burnout tnventory-that is emotional exhaustion, depersonalisation, and personal accomplishment.

Conclusions: Preventative measures, such as increased availability of formal psychological support, should be considered by all trauma units to protect the long term emotional wellbeing of their staff.
$\mathrm{H}$ ealthcare staff working in the emergency department are required to deal with the unpleasant consequences of many traumatic incidents; for instance, violent crime, motor vehicle collisions, and incidents involving injured children. ${ }^{12}$ Staff are also at risk from patients who become violent and aggressive towards them.

Research has begun to identify the effect that traumatic incidents have upon the people caring for trauma victims. Most research studies have focused upon the three emergency services and on the impact that major disasters have upon those who have been involved in the rescue operations. ${ }^{3}$ However, it is increasingly being recognised that it is not only after major disasters that emergency personnel and healthcare staff are at risk of suffering post-traumatic reactions.

Serial exposure to critical incidents may also increase the risk of developing other long term psychological problems, such as professional burnout. Burnout results in the progressive loss of the employees' ability to feel emotionally involved in their work. They develop cynical attitudes towards their patients, thereby compromising the quality of care that they feel able to provide. Healthcare staff suffering from burnout also evaluate their work with patients in a negative light, leaving them feeling dissatisfied with their work.

An increased risk of experiencing burnout has previously been linked to a number of factors relating to the work environment of health professionals. These include increased workload, low level of job satisfaction, conflict with other staff, death and dying, a low degree of support from supervisors, dealing with patients' suffering, and exposure to violent patients. ${ }^{5-11}$

Regularly dealing with violent patients was found to be in the top three sources of occupational stress for nurses working in emergency departments. ${ }^{12}$ The long term emotional reactions experienced by nursing staff include frustration, self blame, helplessness, irritability, depression, and difficulty sleeping. ${ }^{13-15}$ The victims of work related assault have also been shown to be at risk of suffering from symptoms of posttraumatic stress disorder. ${ }^{16}{ }^{17}$

Therefore, exposure to critical incidents and dealing with violent patients represent two of the many occupational hazards associated with working in an emergency department and may conduce to the development of post-traumatic symptoms or professional burnout.

South Africa is one of the most violent countries in the world. A study of the major trauma treated within the Johannesburg Hospital Trauma Unit found that $60 \%$ of all resuscitations were attributable to assault. ${ }^{18}$ Motor vehicle and pedestrian vehicle collisions are also a major cause of death in South Africa. The healthcare staff working within emergency departments in South Africa are therefore exposed to a very high level of trauma. This survey was conducted to assess the effects upon healthcare staff who deal with multiple trauma victims and are themselves subject to violence from patients.

\section{METHODS \\ Subjects}

The Johannesburg Hospital Trauma Unit is based at a multidisciplinary teaching hospital with about 1200 beds located in the centre of the city of Johannesburg. It is a State Health Service Hospital, operated by the Gauteng Provincial Administration. The trauma unit is a level l trauma centre and cares for patients with minor injuries to those with major polytrauma, treating over 18000 patients each year, including 1700 major resuscitations. ${ }^{18}$

The staff members eligible for inclusion in the study were defined as all full time and part time staff (both nurses and

Abbreviations: $C M C$, coping methods checklist; IES-R, impact of event scale-revised; MBI, Maslach burnout inventory 
doctors) working within the Johannesburg Hospital Trauma Unit during September 2002. A comprehensive list of the names of these staff members was supplied by the trauma coordinator responsible for the unit, with a total of 42 staff members forming the study sample (19 nurses and 23 doctors).

Ethical approval for the study was obtained from The Committee for Research on Human Subjects (Medical), University of Witwatersrand, Johannesburg.

\section{Measures}

A questionnaire was specifically designed for the study as no relevant, validated questionnaire was found to be suitable. However, a number of the questions included within the booklet were similar to those used in a previously published research study of staff attitudes towards violent patients, conducted in Aberdeen, Scotland. ${ }^{11}$

The issues to be addressed in the questionnaire booklet were initially identified through a review of published literature, and then discussed with the staff members to ensure that locally relevant issues were also being addressed. The final questionnaire booklet explored a number of issues including: (1) the frequency of exposure to violent and aggressive patients during the previous two years, (2) identification of the types of traumatic incidents considered to be "emotionally distressing", and the coping methods used after these incidents, and (3) the long term psychological sequelae of working in a trauma unit, in terms of changes in attitudes and the development of professional burnout.

The exposure of staff to violent patients was based on the following standard definitions provided within the questionnaire booklet.

(1) Verbal abuse: harassment, threats or other unpleasantness that the participants found damaging, which was directed at them from a patient.

(2) Threatened assault: threatening or aggressive behaviour that the participants found damaging and which was directed at them from a patient, but did not result in physical injury.

(3) Violence: an incident in which the participant was physically abused, assaulted, or otherwise injured by a patient.

The coping methods checklist (CMC), ${ }^{3}$ a list of eight potential coping methods, was used to assess the ways in which staff coped with the demands of their work and the extent to which they found certain methods helpful/unhelpful. Two standardised measures, the impact of event scalerevised (IES-R $)^{19}$ and the Maslach burnout inventory $(\mathrm{MBI}),{ }^{20}$ were also included within the questionnaire booklet.

The IES-R quantifies the post-traumatic symptoms experienced by a respondent after a specific life event. The responses to the 22 individual questions are combined to produce a total subjective stress score as well as three subscales scores of "intrusion", avoidance", and "hyperarousal". The higher the total score, the greater is the degree of psychological impact that an event has had upon a respondent.

The MBI measures the extent of "burnout" by means of 22 statements about personal feelings or attitudes towards an individual's work, each of which has been assigned to one of three sub-scales, "emotional exhaustion", "depersonalisation", and "personal accomplishment". The higher the score of both the emotional exhaustion and depersonalisation subscales and the lower the score of the personal accomplishment sub-scale, the greater the degree of burnout. Therefore, the score for each of the sub-scales must be considered separately to assess the level of burnout.

\section{Procedure}

The questionnaire booklets were given out personally over a five day period to each member of staff of the trauma unit. A short explanation was also given to explain the purpose of the study and the format of the booklet. Participation was voluntary.

All of the questionnaire booklets were assigned an individual identification number when distributed. By this means it was possible to use targeted reminders to increase the overall response rate. The purpose of this identification number was explained to staff and they were reassured that it would be removed immediately upon receipt of the completed questionnaire booklet to ensure that their responses remained anonymous.

Completed questionnaire booklets were placed in a sealed box located within the staff area of the trauma unit. The responses were entered into a Microsoft Excel database, using a previously devised coding scheme, and analysed to produce descriptive statistics. SPSS for Windows (version 9.0) was used to conduct the univariate analyses, which were the $\chi^{2}$ test of independence and Mann-Whitney U test.

\section{RESULTS}

A total of 38 satisfactorily completed questionnaires were returned, a response rate of $90 \%$. Most respondents were nurses $(42 \%)$, with medical officers $(31 \%)$, registrars $(11 \%)$, and consultants $(16 \%)$ representing rest of the respondents. Forty five per cent of all respondents were female, $71 \%$ of whom were nurses, while $81 \%$ of male respondents were doctors.

\section{Exposure to violent/aggressive patients}

During the previous two years, $92 \%$ of trauma unit staff had experienced verbal abuse, $76 \%$ had experienced threatened assault, and $42 \%$ had experienced patient violence. Only three of the 38 staff members reported that they had not experienced any type of violent incident during the previous two years within the trauma unit.

Most staff who reported having experienced threatened assault or violence had been involved in between one and five incidents during the previous two years. However, most of these respondents had experienced verbal abuse on over 16 occasions during the previous two years. In addition, $18 \%$ of trauma unit staff had experienced threatened assault, and more than 1 in 10 had experienced violence on over 16 occasions during the previous two years (fig l).

The association between the staff members' experience of violent incidents and their demographic characteristics was examined by means of the $\chi^{2}$ test. A significant association was found in relation to "current job", with a greater proportion of nurses reporting having experienced "violence" $(\mathrm{p}=0.03)$.

\section{"Emotionally distressing" incidents}

The respondents were given a list of critical incidents and asked to indicate the extent to which they found each type of incident "emotionally disturbing". Incidents involving injured children or sexual assault were reported to be either "quite a bit" or "extremely" emotionally disturbing by $71 \%$ and $61 \%$ of respondents, respectively. Suicides were found to be the least distressing events (table 1).

The respondents were also asked to identify the "most distressing" incident in which they had personally been involved in during the past six months of their career. The psychological impact of this incident was assessed by means of the IES-R. Most staff had a low total score (median $=17.5$, range $=0-88$ ).

The IES-R total scores were compared with the demographic profile of the responders to identify any differences 


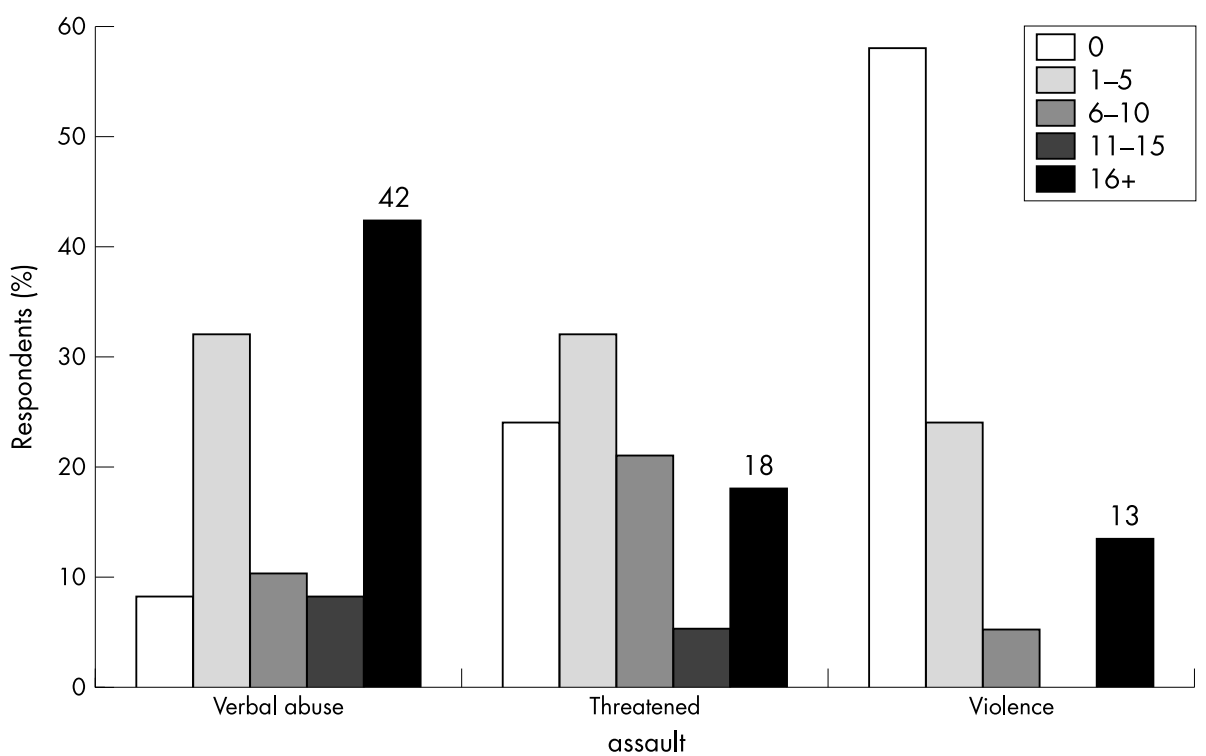

Figure 1 Percentage of respondents exposed to verbal abuse, threatened assault, and violence during the previous two years.

between specific groups of staff. Analyses of data by means of the Mann-Whitney $U$ test identified no significant differences in the IES-R total scores reported by staff in terms of their length of time working in the trauma unit $(p=0.27)$. However, a significant difference was found in terms of sex $(p=0.004)$, and whether they were a nurse or a doctor $(p=0.003)$, with female staff members and nurses found to have higher total scores.

The number of staff who reported using each of the items within the CMC after their "most distressing" event, as well as the number who described each method as "very helpful", is shown in table 2 .

"Talking with colleagues" was the coping method used by the greatest number of respondents $(n=33)$. This coping method was also reported as "very helpful" by $47 \%$ of these staff. However, although over half of the trauma unit staff had tried to cope by keeping their thoughts and feelings to themselves, only $8 \%$ had found it a "very helpful" means of coping.

Only one of the staff had been offered any psychological help following the "most distressing" incident that they had experienced during the previous six months. However, all of the staff members who were not offered this type of help believed that it should be available to them.

Long term effects of working in a trauma unit

The degree of professional burnout reported by the group of nursing and medical staff was assessed by means of the MBI $(\mathrm{n}=38)$. The sub-scales scores for each staff member were categorised according to the validated cut off points published with the standardised measure into "low", "moderate", and "high" degrees of burnout (table 3).

Eighty two per cent of staff felt that their attitudes towards patients had changed from when they first began working in the trauma unit. Almost two thirds of respondents (65\%) indicated that they felt either "more unsympathetic" or "a lot more unsympathetic" towards patients since they began working in the trauma unit.

Forty per cent of trauma unit staff described their job as "very rewarding", and a further $37 \%$ described it as "fairly rewarding". However, four members of staff described their work at the trauma unit as "very unrewarding".

\section{DISCUSSION}

The trauma unit staff who participated in the survey reported a high level of exposure to violent/aggressive patients. More than one in four had experienced patient violence; over three quarters had experienced threatened assault, and nearly all had experienced verbal abuse. Many had experienced these types of violence on more than one occasion. Nursing staff were found to be at greater risk of experiencing patient violence than medical staff, in line with the findings of previous research studies. ${ }^{21-24}$

The direct comparison of rates of exposure to verbal abuse, threats, and physical violence with those described in previous studies is limited by fundamental differences in

\begin{tabular}{|c|c|c|c|c|c|c|c|c|c|c|}
\hline \multirow[b]{2}{*}{ Type of incident } & \multicolumn{2}{|c|}{ Extremely } & \multicolumn{2}{|c|}{ Quite a bit } & \multicolumn{2}{|c|}{ Moderately } & \multicolumn{2}{|c|}{ A little bit } & \multicolumn{2}{|c|}{ Not at all } \\
\hline & $\mathrm{n}$ & $\%$ & $n$ & $\%$ & $n$ & $\%$ & $n$ & $\%$ & $n$ & $\%$ \\
\hline Injured children & 11 & 29 & 16 & 42 & 8 & 21 & 1 & 3 & 2 & 5 \\
\hline Rape or sexual assault & 11 & 29 & 12 & 32 & 11 & 29 & 2 & 5 & 2 & 5 \\
\hline Fires & 10 & 26 & 10 & 26 & 10 & 26 & 5 & 14 & 3 & 8 \\
\hline Facial injuries & 9 & 24 & 1 & 3 & 9 & 24 & 12 & 31 & 7 & 18 \\
\hline Shootings & 8 & 21 & 5 & 13 & 12 & 32 & 5 & 13 & 8 & 21 \\
\hline Stabbings & 8 & 21 & 3 & 8 & 10 & 26 & 8 & 21 & 9 & 24 \\
\hline Motor vehicle accidents & 6 & 16 & 4 & 10 & 11 & 29 & 9 & 24 & 8 & 21 \\
\hline Pedestrian vehicle accidents & 6 & 16 & 3 & 8 & 10 & 26 & 8 & 21 & 11 & 29 \\
\hline Suicides/attempted suicides & 2 & 5 & 3 & 8 & 6 & 16 & 12 & 32 & 15 & 39 \\
\hline
\end{tabular}


Table $2 \mathrm{CMC}$-methods used and their helpfulness

\begin{tabular}{|c|c|c|c|c|}
\hline & \multicolumn{2}{|c|}{ Used } & \multicolumn{2}{|c|}{ "Very helpful" } \\
\hline & $\mathbf{n}$ & $\%$ & $\mathbf{n}$ & $\%$ \\
\hline Talking with colleagues & 33 & 87 & 18 & 47 \\
\hline $\begin{array}{l}\text { Thinking about positive } \\
\text { benefits of your work }\end{array}$ & 30 & 79 & 12 & 32 \\
\hline Looking forward to off duty & 28 & 74 & 14 & 37 \\
\hline $\begin{array}{l}\text { Thinking about outside } \\
\text { interests/distractions }\end{array}$ & 22 & 58 & 8 & 21 \\
\hline $\begin{array}{l}\text { Keeping thoughts/feelings } \\
\text { to yourself }\end{array}$ & 22 & 58 & 3 & 8 \\
\hline Black humour & 21 & 55 & 5 & 13 \\
\hline Thinking about own family & 20 & 53 & 4 & 11 \\
\hline $\begin{array}{l}\text { Avoid thinking about what } \\
\text { you are doing }\end{array}$ & 18 & 47 & 3 & 8 \\
\hline
\end{tabular}

study samples, definitions of violence, and time periods over which data are collected. However, the level of violence reported in this study seems to be either comparable to, or higher than, the level reported in previous studies of "high risk" healthcare staff, such as nursing staff. ${ }^{24-26}$

The investigation of the psychological implications of treating trauma victims showed that the most distressing types of incidents were those involving injured children, a finding similar to those of other studies. ${ }^{27}{ }^{28}$ Sexual assault and fires were also rated as "extremely" distressing by a significant proportion of respondents.

The psychological impact of the "most distressing" critical incident experienced during the previous six months was assessed by means of the IES-R. Compared with the levels reported in a study of Scottish ambulance personnel ${ }^{28}$ these data suggest a significant level of post-traumatic symptomatology among the South African staff. Female members of staff and nurses were also found to have higher IES-R total scores. However, as being a nurse was significantly associated with being female, the difference observed in this sample may be attributable to either or both of these variables.

Most trauma unit staff relied upon the support of their colleagues after these incidents. This is consistent with the findings of previous studies of the coping methods used by nursing staff and other health professionals after distressing events at work. ${ }^{24}$ 28-30

The mean MBI sub-scale scores for emotional exhaustion, depersonalisation, and personal accomplishment of the participants were representative of a high level of burnout in trauma unit staff. The proportion of trauma unit staff reporting a "high" degree of burnout was about 1.5-fold greater, in terms of both emotional exhaustion $(61 \%$ versus $40 \%)$ and depersonalisation (50\% versus 34\%), than the occupational groups found to have the highest risk of burnout in published research studies. ${ }^{5} 78103132$

Yet, the proportion of staff who reported a decreased level of personal accomplishment was similar to other groups of health care professionals. This may show that the demanding yet rewarding nature of the work of trauma unit staff may protect them from experiencing a diminished sense of

Table $3 \mathrm{MBI}$ categories-low, moderate, and high degrees of burnout

\begin{tabular}{llll}
\hline & Low (\%) & Moderate (\%) & High (\%) \\
\hline Emotional exhaustion & 21 & 18 & 61 \\
Depersonalisation & 26 & 24 & 50 \\
Personal accomplishment & 16 & 34 & 50 \\
\hline
\end{tabular}

personal accomplishment to the same extent as the increased emotional exhaustion and depersonalisation that they experience. This hypothesis is supported by other findings in this survey, as $65 \%$ of staff felt that they had become less sympathetic towards patients, yet over three quarters of trauma unit staff described their job as either "very rewarding" or "fairly rewarding".

\section{Conclusions}

The occupational hazards of prolonged exposure to critical incidents and violent patients should be a major concern for healthcare staff working within emergency departments and their employers in light of the findings of this and previous research studies. Although many staff may not wish to use the help offered to them, professional psychological help should be made accessible to all staff.

Future research, using a prospective design, should be conducted to identify the risk factors related to subsequent post-traumatic symptoms, and methods of ameliorating the adverse, long term consequences of working in an emergency department.

\section{CONTRIBUTORS}

The study was initiated by KDB, DAA, and DMGB. The questionnaire booklet was designed by JMC and DMGB, who also devised the study procedure and distributed the questionnaire booklets. JMC was responsible for the collection of completed questionnaires and the coding of all data. Analysis of the data was conducted by JMC and SK. JMC wrote the paper and all authors contributed to drafting the final article. JMC is guarantor of the data.

\section{Authors' affiliations}

J M Crabbe, Faculty of Medicine, University of Aberdeen, UK D M G Bowley, K D Boffard, Johannesburg Hospital Trauma Unit, Johannesburg Hospital, Republic of South Africa

D A Alexander, S Klein, Aberdeen Centre for Trauma Research, Royal Cornhill Hospital, UK

Funding: we wish to thank the Malcolm Millar Fellowship, the Society of Occupational Medicine Scottish Group and the British Medical and Dental Students' Trust for their financial support of this research study.

Conflicts of interest: none declared.

\section{REFERENCES}

1 Beaton R, Murphy S, Johnson C, et al. Coping responses and post-traumatic stress symptomatology in urban fire service personnel. J Trauma Stress 1999; 12:293-308.

2 Clohessy S, Ehlers E. PTSD symptoms, response to intrusive memories and coping in ambulance service workers. Br J Clin Psychol 1999;38:251-65.

3 Alexander DA, Wells A. Reactions of police officers to body-handling after a major disaster. A before-and-after comparison. Br J Psychiatry 1991;159:547-55.

4 Luce A, Firth-Cozens J, Midgley S, et al. After the Omagh bomb: posttraumatic stress disorder in health service staff. J Trauma Stress 2002; 15:27-30.

5 Papadatou D, Anagnostopoulos F, Monos D. Factors contributing to the development of burnout in oncology nursing. Br J Med Psychol 1994;67:187-99.

6 Lee V, Henderson MC. Occupational stress and organizational commitment in nurse administrators. J Nurs Adm 1996;26:21-8.

7 Ramirez AJ, Graham J, Richards MA, et al. Mental health of hospital consultants: the effects of stress and satisfaction at work. Lancet 1996;347:724-8

8 Guthrie E, Tattan T, Williams E, et al. Sources of stress, psychological distress and burnout in psychiatrists. Psychiatr Bull 1999;23:207-12.

9 Hayter M. Burnout and AIDS care-related factors in HIV community clinical nurse specialists in the North of England. J Adv Nurs 1999;29:984-93.

10 Payne N. Occupational stressors and coping as determinants of burnout in female hospice nurses. J Adv Nurs 2001;33:396-405.

11 Crabbe JM, Alexander DA, Klein S, et al. Dealing with violent and aggressive patients: At what cost to nurses? Ir J Psychol Med 2002;19:121-4.

12 Waters J. A\&E staff experience burnout as workloads rise and morale falls. Nurs Times 1996;92:6.

13 Budd T. Violence at work: findings from the British Crime Survey. London: HMSO, 1999.

14 Findorff-Dennis MJ, McGovern PM, Bull M, et al. Work related assaults. The impact on victims. AAOHN 1999;47:456-65. 
15 Gates DM, Fitzwater E, Meyer U. Violence against caregivers in nursing homes. Expected, tolerated and accepted. J Gerontol Nurs 1999;25:12-22.

16 Jenkinson WR. Attacks on postmen in Northern Ireland. What features of the attacks are associated with prolonged absence from work? Occup Med 1993:43:39-42.

17 Kamphuis JH, Emmelkamp PMG. Crime-related trauma: Psychological distress in victims of bankrobbery. J Anxiety Disord 1998;12:199-208.

18 Bowley D, Khavandi A, Boffard K, et al. The malignant epidemic; changing patterns of trauma. S Afr Med J 2002:92:798-802.

19 Weiss DS, Marmar CR. The impact of event scale-revised. In: Assessing psychological trauma and PTSD. New York: Guildford Press, 1997:399-441. 20 Maslach C, Jackson SE. The measurement of experienced burnout. J Occup Behav 1981;2:99-113.

21 Health Services Advisory Committee. Violence to staff in the health services. London: Library and Information Services, 1987.

22 Stark C, Paterson B, Kidd B. Incidence of assault on staff in the NHS. Nurs Times 1995;91:12.

23 Whittington R, Shuttleworth S, Hill L. Violence to staff in a general hospital setting. J Adv Nurs 1996;24:326-33.
24 Fernandes C, Bouthillette F, Raboud J, et al. Violence in the emergency department: a survey of health care workers. Can Med Assoc J 1999;161:1245-8.

25 Coombes R. Violence: the facts. Nurs Times 1998;94:12-14.

26 Royal College of Nursing Scotland. Mental health nursing in Scotland: future challenges. Edinburgh: RCN, 1999:16-24.

27 Regehr C, Hill J, Glancy GD. Individual predictors of traumatic reactions in firefighters. J Nerv Ment Dis 2000;188:333-9.

28 Alexander DA, Klein S. Ambulance personnel and critical incidents. Br J Psychiatry 2001;178:76-81.

29 Smith ME, Hart G. Nurses' responses to patient anger: from disconnecting to connecting. J Adv Nurs 1994;20:643-51.

30 Nolan P, Dallender J, Soares J, et al. Violence in mental health care: the experiences of mental health nurses and psychiatrists. J Adv Nurs 1999:30:934-41.

31 Guntupalli KK, Fromm RE. Burnout in the internist-intensivist. Intensive Care Med 1996;22:625-30.

32 Kilfedder CJ, Power KG, Wells TJ. Burnout in psychiatric nursing. J Adv Nurs 2001;34:383-96 